\title{
Clinical and Psychosocial Correlates of Post-Herpetic Neuralgia
}

\author{
A. Volpi, ${ }^{1 *}$ A. Gatti, ${ }^{2}$ F. Pica, ${ }^{3}$ S. Bellino, ${ }^{4}$ L.T. Marsella, ${ }^{1}$ and A.F. Sabato ${ }^{2}$ \\ ${ }^{1}$ Department of Public Health, University of Rome "Tor Vergata", Rome, Italy \\ ${ }^{2}$ Department of Surgery, University of Rome "Tor Vergata", Rome, Italy \\ ${ }^{3}$ Department of Experimental Medicine, University of Rome "Tor Vergata", Rome, Italy \\ ${ }^{4}$ Istituto Superiore di Sanità, Rome, Italy
}

Post-herpetic neuralgia is the most challenging and debilitating complication of herpes zoster in the immunocompetent host. Because the effect of treatment is disappointing once the syndrome has developed, it is important to know which factors predict post-herpetic neuralgia occurrence to facilitate selection of herpes zoster patients with a higher risk of developing neuralgia and undertake preventative strategies. The present study aimed at identifying demographic, clinical and psychosocial correlates of postherpetic neuralgia in a sample of 219 immunocompetent patients, who were examined by dermatologists in private practice in Italy and who completed a questionnaire designed to evaluate their clinical and psychosocial profile at the time of clinical diagnosis of herpes zoster and at a follow-up visit 6 months later. In a univariate analysis, post-herpetic neuralgia was associated significantly with older age, longer duration of prodromal pain, greater acute pain intensity, greater extent of rash, presence of abnormal sensations and use of systemic antiviral therapy. Compared to the values at herpes zoster onset, at the follow-up visit patients with post-herpetic neuralgia presented with similar high mean scores of pain intensity, anxiety and depression and greatly reduced quality of life, whereas patients without neuralgia presented with improved scores. In a multivariate model, older age, greater acute pain intensity, greater extent of rash and longer duration of prodromal pain were independently associated with postherpetic neuralgia. The results of this study may help physicians to identify patients with a higher risk of developing post-herpetic neuralgia and undertaking preventative strategies. J. Med. Virol. 80:1646-1652, 2008.

(C) 2008 Wiley-Liss, Inc.

KEY WORDS: chronic pain; herpes zoster; post-herpetic neuralgia; quality of life; shingles

\section{INTRODUCTION}

Herpes zoster results from the reactivation of latent Varicella zoster virus from the dorsal root and some cranial nerve ganglia. Although herpes zoster is not a reportable disease, 200,000-250,000 cases are estimated to occur annually in Italy [Di Luzio Paparatti et al., 1999]. Appropriate treatment controls acute herpes zoster symptoms and reduces the risk of longer term complications [Johnson and Dworkin, 2003]. Chronic pain also termed post-herpetic neuralgia is the most common complication of herpes zoster in immunocompetent host. It is characterized by constant or intermittent burning, itching or aching, with paroxysmal or lancinating pain. Other primary characteristics, such as numbness, tingling and allodynia, also contribute to the burden of post-herpetic neuralgia. Secondary characteristics of post-herpetic neuralgia include sleep disturbance, anorexia and weight loss, chronic fatigue and depression accompanied by social isolation. Post-herpetic neuralgia is also known as the debilitating, chronic pain that persists, in some individuals, for weeks, months or even years after the herpes zoster rash has healed. It causes suffering for the patient and a burden of economic cost on patient, care-givers and healthcare providers. Public awareness of the disease is poor, which may lead to delayed presentation for medical care at an early stage of the disease when antiviral drugs may be most beneficial. Despite advances in antiviral therapy during acute herpes zoster and the more recent introduction of vaccination against Varicella zoster virus [Oxman et al., 2005], post-herpetic neuralgia continues to be a significant clinical problem worldwide, with up to $10-25 \%$ of patients experiencing

None of the Authors has conflicts of interest in relation to the present manuscript.

*Correspondence to: A. Volpi, MD, Malattie Infettive, Dipartimento di Sanità Pubblica, Università di Roma "Tor Vergata", Via Montpellier 1, 00133 Roma, Italy. E-mail: volpi@med.uniroma2.it

Accepted 12 May 2008

DOI 10.1002/jmv.21254

Published online in Wiley InterScience

(www.interscience.wiley.com) 
this condition [Cunningham and Dworkin, 2000]. Prevalence estimates of post-herpetic neuralgia, however, vary widely depending on the definition of postherpetic neuralgia used, the population being studied and the adequacy of data [Coplan et al., 2004; Katz et al., 2004]. Although the definitions used in studies of post-herpetic neuralgia have been arbitrary and often inconsistent in the literature, it has recently been proposed that post-herpetic neuralgia exists when significant pain or dysesthesia persists for 3 or more months after rash healing [Dworkin and Portenoy, 1996]. The effects of post-herpetic neuralgia on physical and emotional functioning have been examined in several studies [Schmader et al., 1990; Dworkin et al., 1992; Dworkin and Portenoy, 1996; Whitley et al., 1999; Dworkin and Shmader, 2001; Nagasako et al., 2002; Thyregod et al., 2004]. Because the effect of treatment is disappointing once the syndrome has developed, it is important to know which factors predict post-herpetic neuralgia occurrence to facilitate selection of herpes zoster patients with a higher risk of developing postherpetic neuralgia and undertake preventative strategies. Previous research identified several predictors of post-herpetic neuralgia [Higa et al., 1988; Dworkin et al., 1992; Dworkin and Portenoy, 1996; Choo et al., 1997; Whitley et al., 1998; Opstelten et al., 2002, 2007; Scott et al., 2003; Jung et al., 2004; Coen et al., 2006] but the prognostic value of combinations of physical and psychosocial predictors, based on multivariable prediction modeling, has not yet been assessed.

The aim of the present study is to analyze the relationship between baseline and 6-month follow-up data from 219 Italian immunocompetent herpes zoster patients to identify demographic, clinical and psychosocial correlates of post-herpetic neuralgia in relation to acute herpes zoster presentation.

\section{MATERIALS AND METHODS Patients}

Five hundred thirty-three patients with a clinical diagnosis of herpes zoster, recruited by dermatologists in private practices nationwide from April to October 2001 on acute herpes zoster presentation, were asked to participate in a study of herpes zoster [Volpi et al., 2007], to complete a questionnaire and to return for a 6-month follow-up visit. Informed consent was obtained from all the patients who accepted. The dermatologists also collected medical and demographic data and provided counseling and therapy where appropriate. Two hundred nineteen patients returned at the follow-up visit.

\section{Data Collection}

The data examined in the present analyses were collected at the baseline visit, which occurred at the time of clinical diagnosis and enrolment, and at a follow-up visit 6 months later. In particular, the following data were analyzed: age, sex, pain intensity, the presence of a prodrome (defined as pain before rash onset) and its duration (range 1-more than 3 days), the extent of rash (rash involving 1, 2, or more than two dermatomes) and its localization, the presence of abnormal sensations (including itch, tingle and allodynia) and the use of systemic antiviral therapy.

At the baseline as well as at the follow-up visit, the physician collected the following information from the patients: demographic data, medical history, history of present disease, distribution of manifestations, clinical expression of disease and treatments. On both occasions, patients were also asked to complete the Short Italian Questionnaire, designed to evaluate the intensity of pain, psychological profile and quality of life [Serafini et al., 2003; Volpi et al., 2007]. It elicits information to reflect the level of anxiety or depression and the perceptions that an individual has about their pain and quality of life (worst pain over last week, physical and social functioning, vitality, physical and emotional role, psychological distress and well-being). Each item was scored between 0 (negative) and 10 (maximum).

In the present study patients presenting with pain rated as " 3 " or more on a scale ranging from 0 ("no pain") to 10 ("pain as bad as you can imagine") in the last week before the follow-up visit were considered as affected by post-herpetic neuralgia.

\section{Statistical Analysis}

Statistical analyses and data processing were performed using SAS software, version 8.2 for Windows ${ }^{\mathrm{TM}}$ All two-sided statistical tests were performed using a 5\% significance level.

Quantitative variables were analyzed by descriptive statistics including mean values, standard deviation, median, minimum and maximum. Clinical and demographic characteristics were analyzed as categorical variables, whereas intensity of pain, anxiety, depression and quality of life were analyzed as continuous variables. The chi-square test for combined data was used to investigate the relationships between the demographic and clinical characteristics of patients with and without post-herpetic neuralgia. Pearson's correlation coefficient was used to investigate differences in the psychosocial variables of patients at the baseline and at the follow-up visit. Logistic regression analysis was performed to analyze the relationship between post-herpetic neuralgia and the variables were significantly associated with post-herpetic neuralgia in the univariate analysis, that is, age, pain intensity, extent of rash, duration of prodromal pain, abnormal sensations and antiviral therapy.

\section{RESULTS}

Two hundred nineteen subjects enrolled in a study on acute herpes zoster presentation returned to the physician office for a follow-up visit 6 months later. They were all Caucasian Italians and were evenly distributed from various areas of the Country (data not shown). The 
median age was 58 years (range 18-82) and $68 \%$ of them were over 50 years of age. There were more females than males (63\% vs. $37 \%$ ). Forty-eight percent of participants in the study had a high school education or university degree.

At the 6-month follow-up visit, 70 patients (32\%) presented with post-herpetic neuralgia: among them, there were more females than males (60\% vs. $40 \%)$, similarly to what happened in patients without postherpetic neuralgia, and more people over 60 years of age than in the group of patients without post-herpetic neuralgia $(64 \%$ vs. $38 \%$, respectively; $P<0.0009)$. Demographic and clinical characteristics of the patients with and without post-herpetic neuralgia when first seen with herpes zoster (at baseline visit) are summarized in Table I.

Patients with and without post-herpetic neuralgia did not differ in relation to the presence of prodromal pain and in the overall localization of rash during acute herpes zoster (Table I). However, the ophthalmic localization resulted to be more frequent than the nonophthalmic localization in patients presenting with post-herpetic neuralgia than in those without postherpetic neuralgia [ $21 \%$ vs. $10 \%$, respectively; $P=0.03$; RR 1.77 (95\% CI 1.12-2.8)].

Patients with and without post-herpetic neuralgia presented differences in relation to the duration of prodromal pain before rash (which was more than 3 days in $75 \%$ of patients with post-herpetic neuralgia vs. $24 \%$ of individuals without post-herpetic neuralgia), the extent of rash (which interested more than one dermatome in $43 \%$ of patients with post-herpetic neuralgia vs. $27 \%$ in those without post-herpetic neuralgia) and the intensity of pain at the baseline visit (mean score of pain intensity: 7.0 in patients with post-herpetic neuralgia vs. 5.5 in patients without post-herpetic neuralgia; $P<0.0155)$. The presence of abnormal sensations on acute herpes zoster presentation was detected in $47 \%$ of patients who subsequently developed post-herpetic neuralgia versus $34 \%$ of those who did not $[P=0.047$; RR 1.5 (95\% CI: 1.02-2.22)]. At the follow-up visit, 31\% of patients with post-herpetic neuralgia referred the persistence of abnormal sensations.

Acyclovir, Valaciclovir or Famciclovir had been prescribed according to the guidelines [Volpi et al., 2005], within $72 \mathrm{hr}$ from rash onset, in $79 \%$ of patients who developed post-herpetic neuralgia and in 97\% of patients without post-herpetic neuralgia $(P<0.001)$.

The psychosocial characteristics of patients with and without post-herpetic neuralgia, when first seen during acute herpes zoster and 6 months later, are shown in Table II. At the follow-up visit, patients with postherpetic neuralgia presented pain intensity similar to that of the baseline visit (median value of scores 6.6 vs. 7.0, respectively). Consistently the mean scores of anxiety, depression and quality of life were similar to those registered on acute herpes zoster presentation. On the contrary, patients without post-herpetic neuralgia presented with significantly lower levels of anxiety and depression and improved quality of life with respect to

TABLE I. Demographic and Clinical Characteristics of Patients With and Without Post-Herpetic Neuralgia on Acute Herpes Zoster Presentation

\begin{tabular}{|c|c|c|c|}
\hline & $\mathrm{PHN}^{\mathrm{a}}, \mathrm{N}(\%)$ & No PHN, N (\%) & $P$ \\
\hline Number $(\%)$ & $70(32)$ & $149(68)$ & \\
\hline Gender (Male/Female) & $28(40) / 42(60)$ & $54(36) / 95(64)$ & 0.5920 \\
\hline \multicolumn{4}{|l|}{ Age } \\
\hline$<50$ & $13(19)$ & $57(38)$ & \\
\hline $50-60$ & $12(17)$ & $35(24)$ & \\
\hline$>60$ & $45(64)$ & $56(38)$ & 0.0009 \\
\hline \multicolumn{4}{|l|}{ Years of education } \\
\hline Elementary & $25(40)$ & $42(29)$ & \\
\hline Secondary & $14(23)$ & $25(17)$ & \\
\hline High school/University degree & $23(37)$ & $79(54)$ & 0.0795 \\
\hline Prodromal pain & $52(84)$ & $123(83)$ & 0.89 \\
\hline \multicolumn{4}{|c|}{ Duration of prodromal pain before rash (days) } \\
\hline 1 & $1(2)$ & $18(15)$ & \\
\hline $2-3$ & $12(23)$ & $75(61)$ & \\
\hline$>3$ & $39(75)$ & $30(24)$ & 0.001 \\
\hline Intensity of pain (median value) & 7.0 & 5.50 & 0.0155 \\
\hline \multicolumn{4}{|l|}{ Localization of rash } \\
\hline Ocular & $13(21)$ & $14(10)$ & \\
\hline Cranial & $2(3)$ & $11(8)$ & \\
\hline Cervical & $9(15)$ & $20(14)$ & \\
\hline Thoracic & $32(52)$ & $74(51)$ & \\
\hline Lumbar & $6(10)$ & $26(18)$ & 0.11 \\
\hline \multicolumn{4}{|l|}{ Extent of rash (dermatomes) } \\
\hline 1 & $36(58)$ & $105(73)$ & \\
\hline 2 & $24(39)$ & $35(24)$ & \\
\hline$>2$ & $2(3)$ & $4(3)$ & 0.0354 \\
\hline Abnormal sensations & $33(47)$ & $51(34)$ & 0.047 \\
\hline Systemic antiviral therapy & $55(79)$ & $145(97)$ & $<0.001$ \\
\hline
\end{tabular}

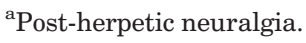


TABLE II. Psychosocial Characteristics of Herpes Zoster Patients at the Baseline and at the 6-month Follow-Up Visit (Median Values of the Scores)

\begin{tabular}{|c|c|c|c|c|c|c|c|c|c|c|}
\hline & \multicolumn{3}{|c|}{$\begin{array}{l}\text { Acute Herpes zoster } \\
\text { (baseline) }\end{array}$} & \multicolumn{3}{|c|}{ Follow-up visit } & \multicolumn{4}{|c|}{$\begin{array}{l}\text { Difference between baseline and } \\
\text { follow-up visits }\end{array}$} \\
\hline & $\mathrm{PHN}^{\mathrm{a}}$ & No PHN & $P^{*}$ & PHN & PHN & $P$ & $\mathrm{PHN}$ & $P$ & No PHN & $P$ \\
\hline Anxiety & 5.51 & 4.65 & 0.18 & 5.26 & 4.0 & 0.002 & -0.25 & 0.47 & -0.65 & 0.0005 \\
\hline Depression & 3.65 & 3.40 & 0.19 & 3.85 & 3.0 & 0.003 & +0.20 & 0.78 & -0.40 & 0.027 \\
\hline Quality of life & 5.8 & 5.8 & 0.14 & 5.70 & 6.20 & 0.03 & -0.10 & 0.48 & +0.4 & 0.027 \\
\hline
\end{tabular}

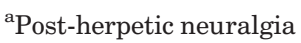

the baseline visit (Table II). Older age, greater pain intensity, longer duration of prodromal pain and greater extent of rash were also shown to be independent predictors of post-herpetic neuralgia by logistic regression analysis (Table III).

\section{DISCUSSION}

In this study older age, greater acute pain intensity, greater rash extent and longer duration of prodromal pain are independent risk factors in the development of post-herpetic neuralgia, as shown by analyzing the relationship between baseline and 6-month follow-up data in a sample of 219 Italian immunocompetent herpes zoster patients.

These and other risk factors have been examined in previous studies that have used a variety of arbitrary definitions of post-herpetic neuralgia [Hope-Simpson, 1965; Dworkin and Portenoy, 1996; Dworkin and Shmader, 2001; Jung et al., 2004].

It is known that there are three phases of pain in herpes zoster: acute herpetic neuralgia, subacute herpetic neuralgia and post-herpetic neuralgia [Arani et al., 2001; Desmond et al., 2002; Jung et al., 2004]. According to the International Herpes Management Forum, post-herpetic neuralgia is defined as the pain persisting beyond 4 months from the onset of the prodrome; the pain between 30 days from a prodrome onset and 4 months is considered subacute herpetic neuralgia; acute herpetic neuralgia is defined as the pain from the onset of herpes zoster to 30 days [Dworkin et al., 2007]. The results of research examining rates of pain resolution in clinical trials of antiviral and corticosteroid therapies in herpes zoster patients, also provide support for defining post-herpetic neuralgia as pain or dysesthesia that persists for 3 or more months after rash healing [Dworkin and Portenoy, 1994]. However, even if long-term post-herpetic neuralgia data are lacking, it is known that post-herpetic neuralgia can last for weeks, months, or even years.

In the present study, patients presenting with pain rated as " 3 " or more on a scale ranging from 0 ("no pain") to 10 ("pain as bad as you can imagine") in the last week before the follow-up visit were considered as affected by post-herpetic neuralgia. At the follow-up visit, 70 (32\%) out of the 219 evaluable patients presented with postherpetic neuralgia according the criteria adopted in this study. This percentage is higher than those previously reported [Johnson and Dworkin, 2003]. A possible bias could be represented by the fact that data from 219 out of an higher number of patients enrolled on acute Herpes zoster presentation [Volpi et al., 2007] were analyzed, since not all of them returned to the physician for the 6-month follow-up visit, possibly for disease resolution. Therefore, the prevalence of post-herpetic neuralgia may be overestimated in this study.

Another potential sampling bias is that patients visiting dermatologists for diagnosis might differ from patients visiting primary care physicians. In this regard, similar studies examining herpes zoster patients on presentation to either dermatologists or general practitioners, did not report significant differences between the two groups [Di Luzio Paparatti et al., 1999; Chidiac et al., 2001; Volpi et al., 2007].

The dilemma regarding both post-herpetic neuralgia definition and comparisons regarding different reports about post-herpetic neuralgia has been illustrated by the recent Shingles UK study of post-herpetic neuralgia prevalence at 26 weeks among patients attending general practices. Using the Zoster Brief Pain

TABLE III. Logistic Regression Model: Risk of Post-Herpetic Neuralgia

\begin{tabular}{|c|c|c|c|c|}
\hline \multirow{2}{*}{$\begin{array}{l}\text { Effect } \\
\text { Class of age (years): } \leq 50 \text { vs. }>50\end{array}$} & \multirow{2}{*}{$\begin{array}{c}\begin{array}{c}\text { Odds Ratio } \\
\text { Estimate }\end{array} \\
0.388\end{array}$} & \multicolumn{2}{|c|}{$\begin{array}{l}95 \% \text { Wald } \\
\text { Confidence Limits }\end{array}$} & \multirow{2}{*}{$\begin{array}{l}P>\chi^{2} \\
0.0049\end{array}$} \\
\hline & & 0.201 & 0.751 & \\
\hline Antiviral therapy: yes vs. no & 0.508 & 0.103 & 2.504 & 0.4056 \\
\hline $\begin{array}{l}\text { Duration of prodromal pain (days): } \\
\leq 3 \text { vs. }>3\end{array}$ & 0.487 & 0.239 & 0.991 & 0.0473 \\
\hline Extent of rash: $\leq 1$ vs. $>1$ dermatome & 0.438 & 0.223 & 0.858 & 0.0162 \\
\hline Intensity of pain & 1.170 & 1.024 & 1.337 & 0.0210 \\
\hline Abnormal sensations & 1.106 & 1.024 & 1.337 & 0.1635 \\
\hline
\end{tabular}


Inventory, a herpes zoster specific questionnaire to quantify zoster pain and discomfort where " $10 "=$ worst imaginable pain, prevalence of post-herpetic neuralgia ranged from $3 \%$ when only pain greater than " 3 " was included to $17 \%$ when including any pain plus abnormal sensations [Scott et al., 2006]. In one German study, the proportion of herpes zoster patients still experiencing pain 4-5 weeks after rash crusting was reported as $28.4 \%$ [Wutzler et al., 1997]. In a retrospective study in the UK, $15 \%$ still had pain 3 months after rash appearance [Bowsher, 1999]. In a meta-analysis, 25\% of placebo-treated patients with herpes zoster reported pain at 6 months [Wood et al., 1996]. At 1 year, approximately $5-10 \%$ of patients still had pain, and spontaneous resolution after post-herpetic neuralgia of this duration is limited [Bowsher, 1999]. Other surveys reported a lower incidence of post-herpetic neuralgia compared with any other published data [Helgason et al., 2000]. Not all studies have included data on pain severity, thereby increasing the difficulty of comparing respective results.

Contrary to some studies [Hope-Simpson, 1975; Meister et al., 1998; Jung et al., 2004] the results reported in this study did not establish female sex as a predictor of post-herpetic neuralgia. Similarly, Dworkin and Shmader [2001] did not find sex differences to be associated with the various aspect of herpes zoster, with the only exception being the intensity of acute pain which is higher in the female gender than in males, as also confirmed by us in a previous study [Volpi et al., 2007]. In the latter study, whereas the univariate analysis suggested that female gender was associated with more severe acute herpes zoster pain, it was shown that in multivariate analysis gender difference was obscured by depression, which was found to be more severe and more frequent in women compared to men [Volpi et al., 2007]. It is also conceivable that the earlier reported association between gender and long-term pain may have been a consequence of the fact that more women were in the higher age strata [Johnson et al., 2003]. Consistently, in the present study we found that among patients with post-herpetic neuralgia there were more females than males, similarly to what happened in patients without post-herpetic neuralgia, but also more people over 60 years of age than in the group of patients without post-herpetic neuralgia.

In the present study, the ophthalmic localization was found to be more frequent in patients presenting with post-herpetic neuralgia than in those without postherpetic neuralgia $[21 \%$ vs. $10 \%$, respectively; $P=0.03$; RR 1.77 (95\% CI 1.12-2.8)], although the present study is unable to assess ophthalmic herpes zoster localization as a predictor of post-herpetic neuralgia, as previously reported by other authors [Hope-Simpson, 1975; Ragozzino et al., 1982; Decroix et al., 2000; Opstelten et al., 2002].

The presence of a prodrome, another potential predictor of post-herpetic neuralgia [Choo et al., 1997; Whitley et al., 1998; Jung et al., 2004], was not found to be associated with post-herpetic neuralgia in the patients examined in this study; however, a longer duration of prodromal pain was significantly associated with post-herpetic neuralgia (Tables I and III). On this point the data available in literature are contrasting. Opstelten et al. [2007] have reported recently that presence and duration of prodromal pain are not predictors of post-herpetic neuralgia. In contrast, multivariate analyses of large-scale studies show that the presence of a prodrome increases the risk of subsequently developing more severe acute zoster pain [Dworkin et al., 2001] and post-herpetic neuralgia [Jung et al., 2004]. There is evidence suggesting that prodromal pain could reflect subclinical Varicella zoster virus reactivation and replication in neural tissue [Garry et al., 2005], but clinical studies evaluating the suitability of Varicella zoster virus as a marker for zoster prodrome found no relationship between viral reactivation and prodromal pain [McKendrick et al., 1999]. The relationship between prodromal pain, Varicella zoster virus and post-herpetic neuralgia is probably more complex than expected and further research is needed to elucidate its nature.

The presence of abnormal sensations (dysesthesia) and the use of systemic antiviral therapy resulted to be significantly associated with post-herpetic neuralgia only in the univariate analysis. It has been shown that abnormal sensations, especially allodynia (pain evoked by the application of a mild, normally non-noxious stimulus), which is common in the first week of rash onset but subsides quickly thereafter in most patients, predicts a higher likelihood of developing post-herpetic neuralgia [Haanpaa et al., 2000]. However, the association was not sufficiently strong to predict post-herpetic neuralgia at an individual level, but the absence of allodynia at presentation was an indicator of good recovery at 3 months. Consistently, in the present study the presence of abnormal sensation was not confirmed as an independent predictor of post-herpetic neuralgia by logistic regression analysis (Table III).

Regarding the use of systemic antiviral treatment, it is generally accepted that antiviral drugs are useful but, unfortunately, they have only a limited effect on post-herpetic neuralgia prevention [Dworkin, 2006]. It has been shown very recently that the prescription of antivirals did not independently predict post-herpetic neuralgia risk [Opstelten et al., 2007], thus clear and accurate statements of their effects are needed.

Finally, it has been reported that psychological processes may contribute to post-herpetic neuralgia development [Dworkin and Banks, 1999; Livengood, 2000]. In a small prospective study, Dworkin et al. [1992] focused their attention on psychosocial postherpetic neuralgia determinants and demonstrated that greater anxiety, greater depression, lower life satisfaction, and greater disease conviction at baseline predicted chronic zoster pain. It has been reported that the severity of the disease at presentation and depression, are the major correlates of pain burden in patients with acute herpes zoster [Katz et al., 2004; Volpi et al., 2007]. However, on the basis of the 6-month follow-up data 
herein reported, it seems more likely that depression is a correlate of both acute and chronic pain intensity, and not an independent predictor of post-herpetic neuralgia.

The present study has some potential limitations, such as the relatively low number of patients examined compared to the number of studied predictors [Concato et al., 1995; Harrel et al., 1996], or the time interval for the follow-up visit, which is longer than in other studies. However, it confirms in an Italian population sample of herpes zoster patients, that older age, greater acute pain intensity, greater rash extent and longer duration of prodromal pain are independent predictors of postherpetic neuralgia. In addition the results reported in this study support the use of antiviral drugs prescription based on age but also on clinical findings (severity of acute pain, greater number of affected dermatomes). The severity of disease on acute herpes zoster presentation, with older age, remain the best indicators of developing post-herpetic neuralgia. The list of these predictors may aid physicians in selecting high-risk herpes zoster patients who may benefit from preventative strategies, or at least should be monitored more closely in the acute period after the rash onset.

\section{ACKNOWLEDGMENTS}

We gratefully acknowledge the contributions of the many dermatologists who participated in this study. We are particularly indebted to Alison Inglis for her linguistic revision of the manuscript.

\section{REFERENCES}

Arani RB, Soong SJ, Weiss HL, Wood MJ, Fiddian PA, Gnann JW, Whitley R. 2001. Phase specific analysis of zoster associated pain data: A new statistical approach. Stat Med 20:2429-2439.

Bowsher D. 1999. The lifetime occurrence of Herpes zoster and prevalence of post-herpetic neuralgia: A retrospective survey in an elderly population. Eur J Pain 3:335-342.

Chidiac C, Bruxelle J, Daures JP, Heang-Xuan T, Morel P, Lepiege A, El Hasnaoui A, de Labareyre C. 2001. Characteristics of patients with Herpes zoster on presentation to practitioners in France. Clin Infect Dis 33:62-69.

Choo PW, Galil K, Donahue JG, Walker AM, Spiegelman D, Platt R. 1997. Risk factors for postherpetic neuralgia. Arch Intern Med 157:1217-1224.

Coen PG, Scott F, Leedham-Green M, Nia T, Jamil A, Johnson RW, Breuer J. 2006. Predicting and preventing post-herpetic neuralgia: Are current risk factors useful in clinical practice? Eur J Pain 10:695-700.

Concato J, Peduzzi P, Holford TR, Feinstein AR. 1995. Importance of events per independent variable in proportional hazards analysis. I. Background, goals, and general strategy. J Clin Epidemiol 48: $1495-1501$.

Coplan PM, Schmader K, Nikas A, Chan Is, Choo P, Levin MJ, Johnson G, Bauer M, Williams HM, Kaplan KM, Guess HA, Oxman MN. 2004. Development of a measure of the burden of pain due to Herpes zoster and postherpetic neuralgia for prevention trials: Adaptation of the brief pain inventory. J Pain 5:344-356.

Cunningham AL, Dworkin RH. 2000. The management of postherpetic neuralgia. Br Med J 321:778-779.

Decroix J, Partsch H, Gonzales R, Mobacken H, Goh CL, Walsh L, Shukla S, Naisbett B. 2000. Factors influencing pain outcome in Herpes zoster: An observational study with valaciclovir. Valaciclovir International Zoster Assessment group (VIZA). J Eur Acad Dermatol Venereal 14:23-33.
Desmond RA, Weiss HL, Arani RB, Soong SJ, Wood MJ, Fiddian PA, Gnann JW, Whitley R. 2002. Clinical applications for change-point analysis of Herpes zoster pain. J Pain Symptom Manage 23:510516.

Di Luzio Paparatti U, Arpinelli F, Visona G. 1999. Herpes zoster and its complications in Italy: An observational survey. J Infect 38:116-120.

Dworkin RH. 2006. Post-herpetic neuralgia. Herpes 13:21A-27A.

Dworkin RH, Banks SM. 1999. A vulnerability-diathesis-stress model of chronic pain: Herpes zoster and the development of postherpetic neuralgia. In: Gatchel R, Turk D, editors. Psychosocial factors in pain-Critical perspectives. New York: The Guilford Press, pp. 247-269.

Dworkin RH, Portenoy RK. 1994. Proposed classification of Herpes zoster pain. Lancet 343:1648.

Dworkin RH, Portenoy RK. 1996. Pain and its persistence in Herpes zoster. Pain 67:241-2451.

Dworkin RH, Shmader KE. 2001. Epidemiology and natural history of Herpes zoster and postherpetic neuralgia. In: Watson CPN, Gershon AA, editors. Herpes zoster and postherpetic neuralgia 2nd edition. New York: Elsevier Press, pp. 39-64.

Dworkin RK, Hartstein G, Rosner HL, Walther RR, Sweeney EW, Brand L. 1992. A high-risk method for studying Psychosocial Antecedents of chronic pain: The prospective investigation of Herpes zoster. J Abnorm Psychol 101:200-205.

Dworkin RH, Nagasako EM, Johnson RW, Griffin DR. 2001. Acute pain in Herpes zoster: The famciclovir database project. Pain 94:113119 .

Dworkin RH, Johnson RW, Breuer J, Gnann JW, Levin MJ, Backonja M, Betts RF, Gershon AA, Haanpaa ML, McKendrick MW, Nurmikko TJ, Oaklander AL, Oxman MN, Pavan-Langston D, Petersen KL, Rowbotham MC, Schmader KE, Stacey BR, Tyring SK, van Wijck AJ, Wallace MS, Wassilew SW, Witley R. 2007. Recommendations for the management of Herpes zoster. Clin Infect Dis 44:S1-S26.

Garry EM, Delaney A, Anderson HA, Sirinathsinghji EC, Clapp RH, Martin WJ, Kinchington PR, Krah DL, Abbadie C, FleetwoodWalker SM. 2005. Varicella zoster virus induces neuropathic changes in rat dorsal root ganglia and behavioural reflex sensitisation that is attenuated by gabapentin or sodium channel blocking drugs. Pain 118:97-111.

Haanpaa M, Laippala P, Nurmikko T. 2000. Allodynia and pinprik hypesthesia in acute Herpes zoster, and the development of postherpetic neuralgia. J Pain Symptom Manage 20:50-58.

Harrel FE, Jr., Lee KL, Mark DB. 1996. Multivariable prognostic models: Issues in developing models, evaluating assumptions and adequacy, and measuring and reducing errors. Stat Med 15:361-387.

Helgason S, Petursson G, Gudmundsson S, Sigurdsson JA. 2000 Prevalence of postherpetic neuralgia after a first episode of Herpes zoster: Prospective study with long-term follow-up. Br Med J 321:794-796

Higa K, Dan K, Manabe H, Noda B. 1988. Factors influencing the duration of treatment of acute herpetic pain with sympathetic nerve block: Importance of severity of Herpes zoster assessed by the maximum antibody titers to varicella-zoster virus in otherwise healthy patients. Pain 32:147-157.

Hope-Simpson RE. 1965. The nature of Herpes zoster: A long-term study and a new hypothesis. Proc R Soc Med 58:9-20.

Hope-Simpson RE. 1975. Postherpetic neuralgia. J R Coll Gen Pract 25:571-575.

Johnson RW, Dworkin RH. 2003. Treatment of Herpes zoster and postherpetic neuralgia. Br Med J 326:748-750.

Jung BF, Johnson RW, Griffin DRJ, Dworkin RH. 2004. Risk factors for postherpetic neuralgia in patients with Herpes zoster. Neurology 62:1545-1551.

Katz J, Cooper EM, Walther RR, Sweeney EW, Dworkin RH. 2004 Acute pain in Herpes zoster and its impact on health-related quality of life. Clin Infect Dis 39:342-348.

Livengood JM. 2000. The role of stress in the development of Herpes zoster and postherpetic neuralgia. Curr Rev Pain 4:7-11.

McKendrick MW, Care CC, Kudesia G, Bates CJ, Oxley MK, Eley A 1999. Is VZV reactivation a common cause of unexplained unilateral pain ? Results of a prospective study of 57 patients. J Infect 39:209-212.

Meister W, Neiss A, Gross G, Doerr HW, Hobel W, Malin JP, von Essen J, Reinmann BY, Witke C, Wutzler P. 1998. A prognostic score for postherpetic neuralgia in ambulatory patients. Infection 26:359363 . 
Nagasako EM, Johnson RW, Griffin DRJ, Dworkin RH. 2002. Rash severity in Herpes zoster: Correlates and relationship to postherpetic neuralgia. J Am Acad Dermatol 46:834-839.

Opstelten W, Mauritz JW, de Wit NJ, van Wijck AJM, Stalman WA, van Essen GA. 2002. Herpes zoster and postherpetic neuralgia: Incidence and risk indicators using a general practice research database. Fam Pract 19:471-475.

Opstelten W, Zuithoff NPA, van Essen GA, van Loon AM, van Wijck AJM, Kalkman CJ, Verheij TJ, Moons KG. 2007. Predicting postherpetic neuralgia in elderly primary care patients with Herpes zoster: Prospective prognostic study. Pain 132:S52-S59.

Oxman MN, Levin MJ, Johnson GR, Schmader KE, Straus SE, Gelb LD, Arbeit RD, Simberkoff MS, Gershon AA, Davis LE, Weinberg A Boardman KD, Williams HM, Zhang JH, Peduzzi PN, et al. 2005. A vaccine to prevent Herpes zoster and postherpetic neuralgia in Older adults. N Eng J Med 352:2271-2284.

Ragozzino MW, Melton LJ III, Kurland LT, Chu CP, Perry HO. 1982. Population-based study of Herpes zoster and its sequelae. Medicine (Baltimore) 61:310-316

Schmader K, Studenski S, MacMillian J, Grufferman S, Cohen HJ. 1990. Are stressful life events risk factors for Herpes zoster? J Am Geriatr Soc 38:1188-1194.

Scott FT, Leedham-Green ME, Barrett-Muir WY, Hawrami K, Gallagher WJ, Johnson R, Breuer J. 2003. A study of shingles and the development of postherpetic neuralgia in East London. J Med Virol 70:S24-S30.
Scott FT, Johnson R, Leedham-Green ME, Davies E, Edmunds WJ, Breuer J. 2006. The burden of Herpes zoster: A prospective population based study. Vaccine 24:1308-1314.

Serafini G, Gatti A, Volpi A, Costa B, Marsella L, Sabato A. 2003. Short Italian questionnaire for comprehensive evaluation of patients with Herpes zoster. Pain Clinic 15:373-376.

Thyregod H, Rowbotham M, Petersen K. 2004. Psychosocial predictors in the development of postherpetic neuralgia in a high-risk acute Herpes zoster population. J Pain 5:S44.

Volpi A, Gross G, Hercogova J, Johnson RW. 2005. Current management of herpes zoster: The European view. Am J Clin Dermatol 6:317-325

Volpi A, Gatti A, Serafini G, Costa B, Suligoi B, Pica F, Marsella LT, Sabato E, Sabato FA. 2007. Clinical and psychosocial correlates of acute pain in Herpes zoster. J Clin Virol 38:275-279.

Whitley RJ, Shukla S, Crooks RJ. 1998. The identification of risk factors associated with persistent pain following Herpes zoster. J Infect Dis 178:S71-S75.

Whitley RJ, Weiss HL, Soong SJ. 1999. Herpes zoster: Risk categories for persistent pain. J Infect Dis 179:9-15.

Wood MJ, Kay R, Dworkin RH, Soong SJ, Whitley RJ. 1996. Oral acyclovir therapy accelerates pain resolution in patients with Herpes zoster: A meta-analysis of placebo-controlled trials. Clin Infect Dis 22:341-347.

Wutzler P, Doerr HW, von Essen J. 1997. Epidemiology of Herpes zoster. Biotest Bull 5:301-306. 